\title{
Aproximação de alunas do ensino básico do pensamento computacional: relato de experiência de uma oficina de eletrônica
}

\author{
Beatriz Silva de Santana ${ }^{1}$, Claudia Pinto Pereira ${ }^{1}$ \\ ${ }^{1}$ Programa de Pós-Graduação em Ciência da Computação - Universidade Estadual de \\ Feira de Santana (UEFS) \\ Av. Transnordestina, $\mathrm{s} / \mathrm{n}$, Novo Horizonte \\ Feira de Santana -- BA, Brasil -- 44036-900 \\ beatrizsantana@ieee.org, caupinto.sena@gmail.com
}

\begin{abstract}
This report refers to the teaching of computational concepts made possible by means of logic, programming and electronics as a means for the approximation of girls in the area of computing, taking into consideration that, despite the notable increase in the participation of women in the most diverse spheres, computing is still sparsely populated by them. According to the results, this proved to be a positive process in order to promote the awakening of interests, the approximation with the areas of computing and electronics and the breach of prejudices.
\end{abstract}

Resumo. Este relato se refere ao ensino de conceitos computacionais possibilitados por meio da lógica, programação e eletrônica como um meio para a aproximação de meninas da área de computação, levando em consideração que, apesar do notável crescimento da participação das mulheres nas mais diversas esferas, a computação ainda é pouco populada pelas mesmas. De acordo com os resultados, este se mostrou um processo positivo no sentido de promover o despertar de interesses, a aproximação com as áreas de computação e eletrônica e a quebra de preconceitos.

\section{Introdução}

No contexto social vigente, nota-se cada vez mais as conquistas obtidas pelas mulheres. $\mathrm{O}$ acesso ao ensino superior, a maior participação no mercado de trabalho, o direito de voto, entre outros, indicam os avanços alcançados por essa categoria. Porém, essa não é uma realidade geral, ainda existem setores nos quais há o domínio masculino. Entre eles, a área de computação demonstra, em pleno século XXI, ser pouco atrativa para mulheres e tal problema pode ser ocasionado por diversos fatores [Coelho, 2013; Holanda et al., 2017].

As causas da não atração de mulheres pela computação são as mais diversas, indo desde os padrões sexistas impostos pela sociedade, como nos casos em que brinquedos de meninas são definidos com objetos relacionados ao cuidado ou ao lar, e brinquedos de meninos são aqueles que tendem a estimular o pensamento lógico e criacional, como os vídeo games e os jogos de raciocínio lógico, até a falta de contato 
VIII Congresso Brasileiro de Informática na Educação (CBIE 2019)

Anais do XXV Workshop de Informática na Escola (WIE 2019)

com a área durante o período escolar [Silva Júnior \& Mendonça, 2013; Santos et al., 2017].

Dentre as diversas formas possíveis de reverter o quadro atual da participação feminina na área de tecnologia, o ensino de conceitos relacionados ao pensamento computacional (PC) mostra-se atrativo e bem visto [Wing, 2011; Santos et al., 2017]. Para além da participação feminina na computação, o aprendizado do PC estimula habilidades que são consideradas fundamentais no presente século, tais como pensamento crítico, criatividade, comunicação, entre outros [Mioto et al., 2019]. Além do ensino, faz-se necessário ater-se ao modo como os conceitos, completamente novos, são difundidos para as estudantes, de modo que as novas informações possam ser assimiladas às pré-existentes, possibilitando assim uma melhor acomodação aos novos conceitos e a geração de conhecimento [Bamberger, 2014; Piaget, 1996].

Deste modo, no presente relato foi tomado o cuidado inicial de relacionar conceitos computacionais com aqueles já conhecidos pelas estudantes. Assim, foi possível permitir que o conhecimento prévio agisse como um fator impulsionador para novas aprendizagens, o que foi possibilitado por meio da computação desplugada [Scardamalia, 2012; Freire, 2009; Vieira; Passos; Barreto, 2013]. Como continuidade, foi feita a introdução da programação por meio da ferramenta Scratch, que traz a ludicidade da associação com blocos de encaixar para o mundo da programação e, por fim, foram apresentados os conceitos de eletrônica para o público alvo com o uso do Arduino, relacionados ao que havia sido apreendido desde o início da oficina.

Neste artigo, relatamos o desenvolvimento de duas oficinas para alunas do ensino básico, que teve por objetivo a aproximação das mesmas com o pensamento computacional, utilizando a eletrônica como mediadora. Tal escolha foi feita como meio de apresentar a computação de forma ampla, tanto nos aspectos de hardware quanto nos de software, e possibilitar que as participantes pudessem desfrutar de uma possível escolha futura em seguir a área de tecnologia, tendo em vista que o desconhecimento é um dos fatores que limitam tal escolha.

\section{Metodologia}

Para a realização deste trabalho, foi escolhida a pesquisa-ação, que é uma metodologia participativa, na qual há intervenção ativa por parte do pesquisador [Thiollent, 2007]. A intervenção/ação se deu por intermédio de 12 horas de aulas ministradas para as participantes, com as devidos registros que serão apresentados na seção de Resultados. Vale ressaltar que esta pesquisa foi submetida e, previamente, aprovada pelo Comitê de Ética da instituição, com parecer consubstanciado de número 2.910.812.

\subsection{Participantes}

Os participantes da pesquisa, anonimamente referenciados, neste trabalho, como estudantes (E1, E2, e assim sucessivamente), foram 12 alunas do ensino básico da rede pública estadual da cidade de Feira de Santana, entre 15 e 18 anos, selecionadas em função da pequena possibilidade de contato com a área, por conta da falta de oferta de disciplinas relacionadas ao pensamento computacional em tal cenário.

\subsection{Conteúdos abordados}

Inicialmente, foram apresentados conceitos computacionais por meio da computação desplugada, técnica que permite a apresentação de conceitos computacionais sem o uso do computador [Vieira; Passos; Barreto, 2013]. Em seguida, os conteúdos apreendidos 
VIII Congresso Brasileiro de Informática na Educação (CBIE 2019)

Anais do XXV Workshop de Informática na Escola (WIE 2019)

por meio da técnica anterior foram simulados com o auxílio do computador, utilizando a programação com a ferramenta Scratch [Maloney et al., 2010]. Por fim, os conceitos iniciais foram implementados por meio de circuitos eletrônicos, demonstrando as amplas possibilidades da computação. Ademais, nessa última etapa, foram apresentadas formas de interagir com o mundo exterior por meio de sensores.

No Quadro 1, é possível verificar as atividades efetuadas, a descrição de cada uma delas, recursos necessários e duração. O detalhamento de cada uma dessas atividades se encontra na Seção 3.

Quadro 1 - Descrição das atividades

\begin{tabular}{|c|c|c|c|c|}
\hline $\begin{array}{c}\text { Estratégia de } \\
\text { Ensino } \\
\end{array}$ & $\begin{array}{l}\text { Nome da } \\
\text { Atividade } \\
\end{array}$ & Descrição & Recursos & Duração \\
\hline \multirow{2}{*}{$\begin{array}{l}\text { Computação } \\
\text { Desplugada }\end{array}$} & $\begin{array}{l}\text { Caça ao } \\
\text { tesouro }\end{array}$ & $\begin{array}{l}\text { Atividade efetuada sem o uso do } \\
\text { computador, com o intuito de } \\
\text { desenvolver o entendimento de } \\
\text { algoritmos. }\end{array}$ & $\begin{array}{l}\text { Papel, caneta e lápis } \\
\text { de cor. }\end{array}$ & 1 hora \\
\hline & Semáforo & \begin{tabular}{lccr} 
Atividade efetuada & sem o uso do \\
computador, com & o intuito de \\
desenvolver & o & \multicolumn{2}{c}{ conhecimento } \\
relacionado & a & estruturas de \\
condição. & & & \\
\end{tabular} & $\begin{array}{l}\text { Papel, caneta e lápis } \\
\text { de cor. }\end{array}$ & 1 hora \\
\hline $\begin{array}{l}\text { Programação } \\
\text { com Scratch }\end{array}$ & $\begin{array}{l}\text { Conhecend } \\
\text { o o Scratch }\end{array}$ & $\begin{array}{l}\text { Atividade efetuada com o auxílio } \\
\text { do software Scratch, através do } \\
\text { qual é possível conhecer o ambiente } \\
\text { de programação e suas ferramentas, } \\
\text { além de possibilitar a aplicação dos } \\
\text { conhecimentos obtidos } \\
\text { anteriormente. }\end{array}$ & $\begin{array}{l}\text { Computador, } \\
\text { Software Scratch. }\end{array}$ & 2 horas \\
\hline $\begin{array}{l}\text { Ensino dos } \\
\text { Conceitos } \\
\text { Básicos da } \\
\text { Eletrônica }\end{array}$ & $\begin{array}{l}\text { Fundament } \\
\text { os da } \\
\text { eletrônica }\end{array}$ & $\begin{array}{l}\text { Atividade efetuada com o objetivo } \\
\text { de apresentar conceitos básicos de } \\
\text { eletrônica, necessários para as } \\
\text { próximas etapas. }\end{array}$ & $\begin{array}{l}\text { Computador, placa } \\
\text { de prototipagem } \\
\text { Arduino, simulador } \\
\text { Falstad } \\
\text { componentes } \\
\text { (Protoboard, } \\
\text { resistores, fios, } \\
\text { leds). }\end{array}$ & 2 horas \\
\hline $\begin{array}{l}\text { Associação dos } \\
\text { conhecimentos } \\
\text { anteriores da } \\
\text { programação } \\
\text { com a } \\
\text { eletrônica }\end{array}$ & $\begin{array}{l}\text { Projeto } \\
\text { Semáforo }\end{array}$ & $\begin{array}{l}\text { Realizar o projeto de um semáforo } \\
\text { de carros e outro de pedestre, } \\
\text { utilizando estruturas condicionais } \\
\text { para a realização da abertura e } \\
\text { fechamento do semáforo. }\end{array}$ & $\begin{array}{l}\text { Computador, } \\
\text { software S4A, } \\
\text { Arduino } \\
\text { componentes } \\
\text { (Protoboard, } \\
\text { resistores, fios e } \\
\text { leds). }\end{array}$ & 2 horas \\
\hline \multirow{2}{*}{$\begin{array}{l}\text { Capturando } \\
\text { informações do } \\
\text { mundo real }\end{array}$} & $\begin{array}{l}\text { Sensor de } \\
\text { Luz }\end{array}$ & $\begin{array}{l}\text { A atividade consiste em realizar o } \\
\text { controle de luminosidade de um } \\
\text { local. Para tanto é utilizado um } \\
\text { sensor e conceitos de informações } \\
\text { analógicas. }\end{array}$ & $\begin{array}{l}\text { Computador, } \\
\text { software S4A, } \\
\text { Arduino e compo- } \\
\text { nentes (Protoboard, } \\
\text { resistores, fios e } \\
\text { sensor de luz). }\end{array}$ & 1 hora. \\
\hline & Piano de & Atividade efetuada com o auxílio & Computador, & 3 horas \\
\hline
\end{tabular}


VIII Congresso Brasileiro de Informática na Educação (CBIE 2019)

Anais do XXV Workshop de Informática na Escola (WIE 2019)

\begin{tabular}{|c|c|c|c|}
\hline $\begin{array}{l}\text { (programação }+ \\
\text { eletrônica) }\end{array}$ & Frutas & $\begin{array}{l}\text { do S4A e do Arduino, objetivando a } \\
\text { aplicação dos conceitos das aulas } \\
\text { anteriores e possibilitando a } \\
\text { utilização de programação aliada ao } \\
\text { conceito de informações analógicas. }\end{array}$ & $\begin{array}{l}\text { software } \\
\text { Arduino } \\
\text { componentes } \\
\text { (Protoboard, } \\
\text { resistores, fios). }\end{array}$ \\
\hline
\end{tabular}

\subsection{Análise de dados}

Dados qualitativos e quantitativos foram levantados durante o estudo, por meio de questionários, entrevistas e diários de observação. Neste artigo, entretanto, serão apresentados, na Seção 3.6, somente as observações e os dados quantitativos coletados. O objetivo das perguntas, apresentadas no Quadro 2, era o de verificar se as percepções das estudantes se alteraram ao longo do processo, antes e após a intervenção.

\section{Quadro 2 - Perguntas do questionário}

\begin{tabular}{|l|l|}
\hline Q1 & Você considera computação coisa de homem? \\
\hline Q2 & Você considera engenharia coisa de homem? \\
\hline Q3 & Computação é difícil? \\
\hline Q4 & Eletrônica é difícil? \\
\hline Q5 & $\begin{array}{l}\text { Você considera a possibilidade de fazer faculdade na área de tecnologia? (Computação e/ou } \\
\text { engenharia?) }\end{array}$ \\
\hline
\end{tabular}

As duas primeiras perguntas possuíam o objetivo de verificar as percepções em relação à crença de que a área de computação ou engenharia é masculina, enquanto as questões 3 e 4 versam sobre a crença relacionada à dificuldade das áreas afins ao curso e, por fim, a quinta questão buscava verificar se as participantes pretendiam cursar ou, pelo menos, incluía a área de tecnologia como uma possível escolha.

Ao final de cada atividade, foi efetuado um momento de reflexão e as falas que as participantes emitiram, nesse momento, foram levadas em consideração para a análise da intervenção.

\section{Resultados e Discussões}

Foram efetuadas duas oficinas, uma contendo sete alunas e outra, cinco. A primeira foi dividida em seis encontros de duas horas cada; e a segunda, em três encontros de quatro horas. Nas subseções abaixo, trataremos sobre cada estratégia de ensino utilizada para construção do conhecimento.

\subsection{Computação Desplugada}

A primeira atividade efetuada foi uma caça ao tesouro, na qual um grupo de estudantes escondia um objeto na sala e uma das estudantes, que não havia participado do processo de ocultação, se responsabilizava por encontrá-lo. Para tanto, as colegas deveriam fazer um passo a passo detalhado, que deveria ser seguido meticulosamente pela colega. Deste modo, foi possível a prática do conceito de algoritmo, com a definição de uma sequência lógica de procedimentos para atingir um objetivo final. Após a realização da atividade, as estudantes foram convidadas a refletir sobre o processo e o conceito aprendido. Elas demonstraram, naquele momento, não só que sabiam o que era algoritmo, como também sinalizaram que já tinham utilizado o conceito em outros momentos, ainda que não conhecessem o nome 'Algoritmo'. Exemplificaram algoritmos do dia a dia, tais como atravessar uma rua, se locomover até esta oficina e escolher uma roupa. 
VIII Congresso Brasileiro de Informática na Educação (CBIE 2019)

Anais do XXV Workshop de Informática na Escola (WIE 2019)

A segunda atividade desplugada foi responsável por compartilhar com as participantes os conceitos de condicionais e laços de repetições por meio de uma dinâmica do funcionamento de um semáforo. Elas tinham como objetivo descrever, com o auxílio de papel e caneta, as etapas de execução de um semáforo. Após a descrição destas etapas, algumas participantes simularam o seu funcionamento, realizando o papel da troca de cores do semáforo, e outras simularam os objetos de trânsito (carros e pessoas).

\subsection{Conhecendo o Scratch}

O objetivo dessa atividade foi apresentar para as participantes o ambiente de programação Scratch. Para tanto, foi feita uma atividade cujo objetivo era controlar as ações de um ator (personagem do Scratch), para que o mesmo fizesse movimentos prédeterminados, assim como foi feito na atividade desplugada da caça ao tesouro.

Em um segundo momento, foi efetuada a atividade de programação de um semáforo utilizando o algoritmo definido na dinâmica desplugada realizada anteriormente. Nesse momento, as estudantes conseguiram facilmente associar os comando apresentados do Scratch ao algoritmo construído na aula desplugada.

Ao final desta aula, as estudantes demonstraram que a experiência de transformar o que foi efetuado nas atividades desplugadas em algo executável pelo computador foi prazerosa e surpreendente, como pode ser visualizado nas falas abaixo.

“Acho que a gente é um pouco inteligente, né?" (E12);

"Foi legal, porque tudo que a gente fez aqui na sala, a gente botou lá pra poder ver como é que ficava" (E5).

Além disso, externaram, antes da realização das atividades, que a programação no ambiente Scratch seria difícil, entretanto, a conclusão de que não era tão difícil foi um senso comum entre elas, após a finalização do que foi proposto ("Achei que era dificil, antes de mexer" - E11).

\subsection{Fundamentos da eletrônica}

No terceiro momento, foram ensinados os conceitos básicos de eletrônica. Para melhor entendimento da dinâmica do funcionamento de um circuito, foi utilizado o software de simulação falstad $^{1}$. Em seguida, foi feita a montagem um circuito básico, cujo objetivo era o acendimento de um led sem nenhum tipo de programação.

As alunas da primeira turma já conheciam os conceitos de corrente e voltagem, pois os mesmos foram ensinados na escola. Elas demonstraram entender melhor tais conceitos ao visualizar o fluxo da corrente no simulador. Importa informar que essa aula foi executada duas vezes na primeira turma, pois, no dia da primeira execução, metade das alunas faltaram, por diversas razões. Na segunda aplicação da aula, as alunas que participaram da anterior figuraram como tutoras e demonstraram domínio sobre o assunto que haviam apreendido anteriormente, cooperando para o desenvolvimento da aula e de suas colegas.

Nessa aula, a simulação do circuito facilitou o entendimento e o desenvolvimento da montagem do circuito real. O medo inicial das participantes em relação ao manuseio dos componentes, em especial com o receio em danificá-los, assim

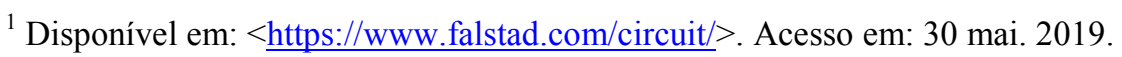


VIII Congresso Brasileiro de Informática na Educação (CBIE 2019)

Anais do XXV Workshop de Informática na Escola (WIE 2019)

como o medo de que ocorressem acidentes, como explosões, choques, entre outros, foram externalizados como nas falas a seguir.

"Não vai rolar fogo aqui não né?" (E14);

"Eu vou é tomar choque" (E8);

"Dá medo de pegar, de soltar uma pecinha dessas, sei lá" (E12).

No momento de reflexão, as participantes compartilharam suas percepções em relação ao aprendizado e foi possível verificar que, assim como na aula anterior, o sentimento inicial era de dificuldade para a realização da prática da aula, sentimento este que se dissipou após a sua realização. As queixas em relação às dificuldades giraram em torno da montagem do circuito, em especial o receio em ter que lembrar a ordem de montagem. Nesse momento, a intervenção foi no sentido de explicá-las sobre a possibilidade de recorrer a esquemas de montagens similares à simulação proposta, exercitando a associação de conceitos/esquemas semelhantes e reforçando o fato de que os processos de memorização e de aprendizagem são graduais [Freire, 2009].

\subsection{Projeto semáforo: associando conhecimentos anteriores}

A aula intitulada "Projeto Semáforo" tinha como objetivo atrelar todos os conceitos trabalhados anteriormente. Para tanto, foi utilizado o software $S 4 A$, que consiste na utilização dos blocos e interface do Scratch para a programação do Arduino, uma placa de circuito impresso programável de baixo custo [Mélo, 2011].

Nessa aula, foi feita a junção dos conhecimentos adquiridos tanto na programação do semáforo no Scratch, quanto na montagem do circuito de um led. As participantes demonstraram certa facilidade na montagem e, nesse momento, foi possível identificar a cooperação presente nos instantes em que se ajudavam mutuamente. Assim como na aula do Scratch, as estudantes demonstraram contentamento ao realizar a montagem e a programação do circuito, o que foi observado por meio de gestos e falas, como, por exemplo, o registro de seus feitos por meio das câmeras dos celulares. Ademais, após a simulação de uma primeira tentativa da realização do circuito, elas conseguiram idealizar modificações e melhorias no circuito montado.

Ao finalizar a atividade, as estudantes inicialmente demonstraram esperar que a programação do circuito tivesse um elevado grau de nível de dificuldade, devido à falta de conhecimento sobre como realizá-la, porém consideraram, após a realização, tal tarefa fácil e divertida. Elas também externaram que, após a montagem e a programação do primeiro led, relativo à primeira cor do semáforo, as etapas seguintes foram simples.

\subsection{Capturando informações do mundo real}

Antes do início dessa etapa, as estudantes foram convidadas a refletir sobre como poderiam obter informações do mundo real, como por exemplo, a proporção de luminosidade de um ambiente. As respostas sempre remetiam a ideia de que era algo muito difícil de ser efetuado e necessitava de um amplo conhecimento. Algumas dessas falas são apresentadas a seguir.

"Eu acho que é muito difícil." (E10);

"99\% dificil" (E12);

"Um pouco dificil” (E3). 
Inicialmente, foi apresentado um sensor de luminosidade e, com ele, as estudantes efetuaram a montagem e a programação de um circuito para simular o acendimento de uma lâmpada quando o ambiente estivesse escuro. Elas atuaram ativamente ao realizar o experimento, assumindo o papel de criador e tornando significativo o próprio processo de aprendizagem [Araujo; Andrade; Guerrero, 2016]. Após a realização da montagem e da programação, assim como anteriormente, as estudantes expressaram admiração em relação ao trabalho que haviam concluído. Dessa forma, o senso comum de que era impossível, para elas, a realização de tal tarefa, foi revertido para algo totalmente viável.

A segunda atividade efetuada nessa etapa foi um piano de frutas. Após a apresentação do objetivo final da atividade, a demonstração foi semelhante à da atividade anterior, ou seja, de que seria difícil para elas a execução e a finalização da tarefa proposta. Porém, em ambas as turmas, elas relembraram, sem auxílio do facilitador, que, nas atividades anteriores, possuíram o mesmo sentimento de incapacidade em relação ao que seria efetuado e que, ao realizar as propostas, perceberam que era algo executável.

Após a realização da programação e da montagem da primeira parte do circuito, as estudantes conseguiram seguir e identificar as próximas etapas com pouco ou nenhum auxílio da facilitadora. Conforme terminavam, elas se disponibilizavam voluntariamente para auxiliar as que estavam mais atrasadas. Ao final da atividade, os pianos eram testados, gravados por suas câmeras de celulares e exibidos com orgulho. $\mathrm{Na}$ Figura 1, é possível visualizar os experimentos realizados nesta segunda atividade.

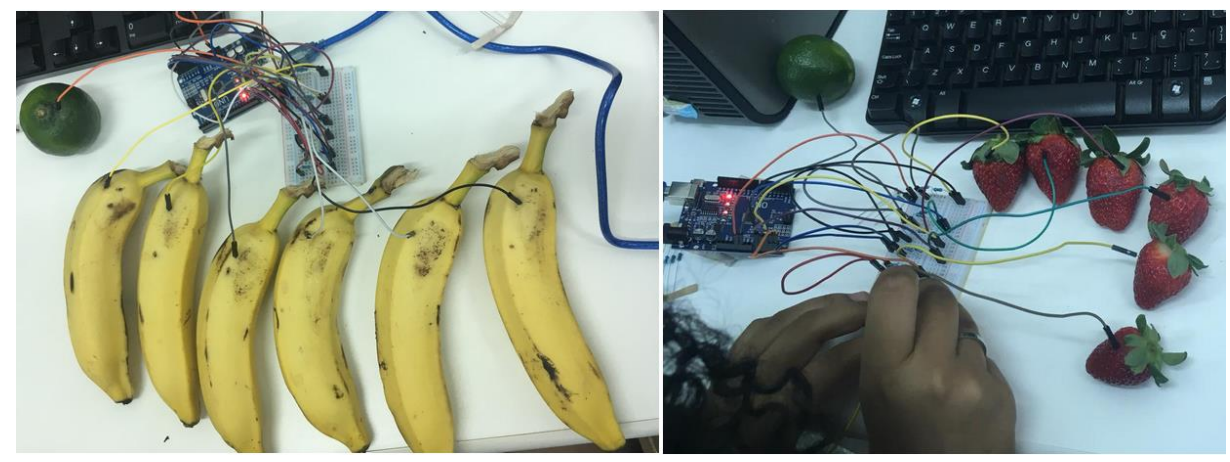

Figura 1. Experimentos da aula - Capturando informações do mundo real

Fonte: Santana (2019)

\subsection{Panorama geral das aulas}

De maneira geral, as participantes conseguiram facilmente associar os assuntos e retomar os conceitos que foram apreendidos sem grande necessidade de repetição.

Outro fator observado, durante as aulas, foi que as estudantes cooperavam tanto para o andamento da aula, quanto para a aprendizagem das colegas, demonstrando facilidade em trabalhar em grupo e bom relacionamento, mesmo com as colegas que não conheciam previamente.

$\mathrm{Na}$ primeira aula, assim como planejado, elas conseguiram trazer para a sala suas experiências prévias, que não eram relacionadas à computação, e utilizá-las na atividade proposta. Deste modo, foi possível criar um ambiente confortável para o aprendizado, e garantir, nos momentos posteriores de aula/oficina, que o relacionamento de conteúdos de aulas anteriores com os novos fosse importante para o processo de 
VIII Congresso Brasileiro de Informática na Educação (CBIE 2019)

Anais do XXV Workshop de Informática na Escola (WIE 2019)

aprendizagem [Scardamalia, 2012]. Além disso, as falas das participantes demonstraram que havia pouco ou nenhum conhecimento prévio relacionado a conceitos computacionais, o que pode corroborar com o afastamento das mulheres em relação à área, mas não pode ser considerado como único elemento distanciador [Bamberger, 2014].

Sempre que uma atividade era exposta, as falas das estudantes demonstravam a expectativa de que houvesse um alto grau de dificuldade, principalmente nas últimas atividades de eletrônica, por serem bem diferentes da realidade das mesmas. Entretanto, durante os momentos de reflexão realizados após cada aula, observaram que tal expectativa não condizia com a realidade, ainda que algumas atividades tivessem sido mais difíceis do que outras, porém não impraticáveis. Durante as aulas, observou-se um sentimento de medo no primeiro contato com o desenvolvimento de circuitos elétricos e, após a sua realização, esse sentimento deu lugar ao de segurança. É importante ressaltar que a aproximação das estudantes de experiências que não são comuns no seu dia a dia é uma forma de quebrar um pré-conceito comumente ocasionado pelo desconhecimento.

Também foi possível notar reações ligadas ao contentamento na realização da atividade, o prazer e a alegria em concluir cada etapa. Além disso, antes das atividades, existia nas estudantes um sentimento de incapacidade para a realização do que havia sido proposto, porém, após a execução, havia manifestações de que "sim" eram capazes daquele feito.

Durante a finalização da oficina, as estudantes externaram seus pensamentos em relação à experiência vivida. $\mathrm{O}$ Gráfico 1 apresenta as respostas dos questionários aplicados antes e após a intervenção, a partir das questões apresentadas no Quadro 2.

Gráfico 1. Respostas às Questões antes e após a oficina

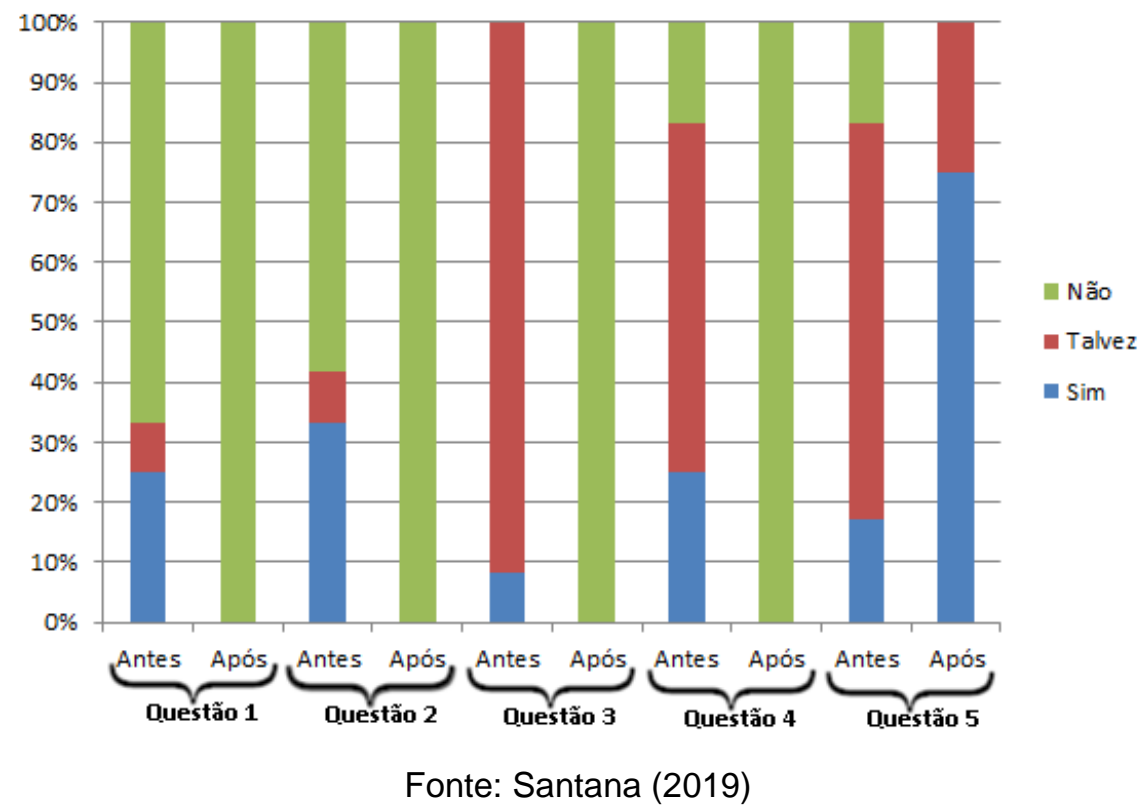

É verificável que as percepções em relação à questão da computação e da eletrônica serem áreas masculinas foram alteradas, assim como a percepção sobre a dificuldade das áreas. Além disso, após a intervenção, a maioria das estudantes demonstrou o interesse de seguir uma carreira na área de tecnologia, o que antes não era 
VIII Congresso Brasileiro de Informática na Educação (CBIE 2019)

Anais do XXV Workshop de Informática na Escola (WIE 2019)

uma opção para algumas, pois o desconhecimento as fazia pensar que não era interessante ou que era uma área difícil. Quando questionadas sobre o assunto (Questão 5), responderam: "Não, porque antes não gostava disso" (E7); "Achava que era chato" (E4); "Achava que eu nunca iria aprender" (E14); "Descobri que é legal, que dá pra entender mais, que não é só computador" (E14); "Antes eu nem sabia o que era. Agora já sei" (E7); "Eu achava que eu ia dar defeito nos computadores tudo" (E8). Uma das estudantes, que relatou ter incluído a computação em suas opções de carreira após a intervenção, compartilhou com o grupo que passou a ver a área como opção, pois havia gostado de realizar as atividades efetuadas durante a oficina.

Durante o momento de reflexão final, também demonstraram satisfação com o trabalho efetuado, e o desejo de que mais aulas fossem oferecidas, percebidos por meio de falas como: "Era pra esse curso durar mais" (E12); "Não acredito que foi a última aula" (E8); "Triste porque hoje é o último dia” (E1).

\section{Considerações Finais}

Neste artigo, tratamos da realização de oficinas de pensamento computacional para estudantes do ensino básico como forma de compreender se as percepções das meninas em relação à tecnologia eram modificadas ao entrarem em contato com conceitos da computação.

Diante dos resultados, depreende-se que, assim como a literatura indica, a falta de contato do público alvo com os conceitos computacionais ocasiona diversos preconceitos que são decisivos para uma escolha em relação a seguir uma carreira na área de tecnologia. Indo além da questão de seguir ou não uma carreira tecnológica, tais conhecimentos são importantes para o desenvolvimento de habilidades pessoais e as mulheres não deveriam ser privadas de tal experiência.

Também foi possível constatar, por parte das estudantes que, após um breve contato com a área, surgiu um interesse em continuar a aprender e a desenvolver as habilidades trabalhadas durante as oficinas. Este cenário evidencia a necessidade de que sejam idealizadas e executadas mais ações envolvendo o ensino de tecnologias para o público do ensino básico, em especial da educação pública.

Neste sentido, espera-se que mais ações no sentido de disseminar o uso da tecnologia de maneira ativa, lúdica e participativa sejam efetuadas com mais participantes de diferentes faixas etárias, para que, dessa forma, seja possível analisar, de maneira mais ampla, o impacto desse contato a longo prazo para as alunas de ensino básico, fundamental ou médio, seja na perspectiva pessoal (e.g. motivação, inclusão social, autoestima), ou na perspectiva acadêmico-profissional (e.g. ingresso em cursos de tecnologia e engenharias, acesso ao mercado de trabalho).

\section{Referências}

Araujo, A. L.; Andrade, W.; Guerrero, D. (2016). Um mapeamento sistemático sobre a avaliação do pensamento computacional no Brasil. In: Anais dos Workshops do Congresso Brasileiro de Informática na Educação. p. 1147. 
VIII Congresso Brasileiro de Informática na Educação (CBIE 2019)

Anais do XXV Workshop de Informática na Escola (WIE 2019)

Bamberger, Y. M. (2014). Encouraging girls into science and technology with feminine role model: Does this work? Journal of Science Education and Technology, v. 23, n. 4, p. 549-561.

Coelho, R. C. (2013). Mulheres e Meninas na Computação: Realidade e Desafio!. Revista Computação Brasil, Porto Alegre, v.7, n. 2, p. 68-80.

Freire, L. G. L. (2009). Auto-regulação da aprendizagem. Ciências \& Cognição, v. 14, n. 2, 2009.

Holanda, M. et al. (2017). Percepção das meninas do ensino médio sobre o curso de computação no Distrito Federal do Brasil. In: Congreso de la Mujer Latinoamericana en Computación (LAWCC-CLEI) - JAIIO 46 Córdoba.

Maloney, J. et al. (2010). The Scratch Programming Language and Environment. ACM Trans. Comput. Educ, v. 10, n. 15.

Mélo, F. É. N. et al.(2011). Do Scratch ao Arduino: Uma proposta para o ensino introdutório de programação para cursos superiores de tecnologia. In: XXXIX Congresso Brasileiro de Educação em Engenharia. p. 10.

Mioto, F. et al. (2019). bASES21-Um Modelo para a Autoavaliação de Habilidades do Século XXI no Contexto do Ensino de Computação na Educação Básica. Revista Brasileira de Informática na Educação, v. 27, n. 1.

Piaget, J. Biologia e Conhecimento. $2^{\text {a }}$ Ed. Vozes: Petrópolis, 1996.

Santana, B. S. (2019). Eletrônica para Mulheres: Estudo do Impacto de Experimentação Lúdica e Coparticipativa com Meninas no Ensino Fundamental, Universidade Estadual de Feira de Santana. Feira de Santana-Bahia.

Santos, C. P. et al. (2017). Explorando o Pensamento Computacional para Despertar Novos Talentos: Relato de uma Experiência. In: $11^{\mathrm{o}}$ Women in Information Technology (WIT 2017). SBC.

Scardamalia, M. et al. (2012). New assessments and environments for knowledge building. In: Assessment and teaching of 21st century skills. Springer, Dordrecht. p. 231-300.

Silva Júnior, J. F. da; Mendonça, S. F. T. de O. (2013). Inserção da mulher na Ciência da Computação no município de Garanhuns. Revista da Escola Regional de Informática, v. 2, n. 2, p. 128-131.

Thiollent, M. (2007). Metodologia da pesquisa-ação. 15. ed. São Paulo: Cortez.

Vieira, A.; Passos, O.; Barreto, R. (2013). Um relato de experiência do uso da técnica computação desplugada. Workshop sobre Educação em Computação, XXI, 2013, Maceió. In: XXI Workshop sobre Educação em Computação, p.670-679. Maceió.

Wing, J. (2011). Research notebook: Computational thinking-What and why. The Link Magazine, p. 20-23. 